\title{
Proyecto moderno: ¿una historia fuera de contexto?
}

\author{
Héctor Ruiz Arias ${ }^{2}$ \\ Luis González Bravo ${ }^{3}$ \\ El problema de la realidad del cuerpo demuestra ser el problema \\ básico, y de su solución depende todo lo demás \\ Gabriel Marcel \\ Diario Metafísico
}

\section{Resumen}

La polémica emic-etic de la sociología cualitativa se reedita desde la investigación empírica y análisis de entrevistas de actores de la vida cotidiana. Como ejemplo, permite presentar una didáctica de construcción de un ensayo sociológico centrado en los conceptos de Estado, Nación y Globalización, caracterizados rudimentariamente por el saber popular de los pasajeros de un taxi colectivo y, al mismo tiempo, contrastados con el saber oficial del cientista social.

1 El presente ensayo fue elaborado sobre la base de 5 entrevistas realizadas a un almacenero, un guardia, un auxiliar, una administrativa de un servicio público y un taxista, a partir de una pauta semi-estructurada en torno a los conceptos de Estado, Nación y Globalización. En la medida que este ensayo intenta señalar la distancia que existe entre la cotidianeidad de los sujetos y la teoría social, la elección de esta forma narrativa pareció una eficiente manera ilustrar dicha distancia. Una disparidad que reedita parcialmente la polémica etic-emic (Gutierrez y Delgado, 1995).

2 Periodista, Magíster (c.) en Investigación Social y Desarrollo, Universidad de Concepción.

3 Psicólogo, Magíster (c.) en Investigación Social y Desarrollo, Universidad de Concepción. 


\section{Palabras clave}

Emic-etic / sociología cualitativa / ensayo sociológico / Estado, Nación y Globalización / saber popular / cientista social.

\section{Abstract}

The emic-etic controversy of qualitative sociology is reedited from the empirical investigation and analysis of interviews to daily life actors. As an example, it permits to display a didactics of construction of a sociological essay centered in the concepts of State, Nation and Globalization, rudimentarily characterized with the popular knowledge of the passengers of a taxi and, at the same time, contrasted with the official knowledge of the social scientist.

\section{Key words:}

Emic-etic / qualitative sociology / sociological essay / State, Nation and Globalization / popular knowledge / social scientist 


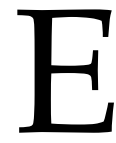

1 mudo frío de la ventana comenzó a dialogar con el sueño, con el sueño violento e interrumpido de una noche en bus. Darse cuenta del vidrio empañado y de que la frazada ya no cubría fue una sola cosa. Siempre le sucedía que se dormía cuando no correspondía y viceversa. Después de una noche tratando de leer los apuntes del curso que dictaba al mediodía en la U de Conce, con una luz que más que soporte fue un verdadero obstáculo a la concentración, olvidó dónde estaba, qué estaba haciendo. Al menos, ese olvido le inyectó la certeza de que debió haber dormido; que estaba bien.

Abajo, la gente que avanzaba como bultos encorvados le recordó su conferencia de la tarde. Globalización. Guardar los apuntes en el bolso, buscar la manta que alguna vez lo había tapado, la chaqueta, la billetera con su carné de profesor universitario, bajar del bus.

Afuera, un frío maldito, "como la vida", creyó. No pensó en ningún autor, lo abatía la lastimosa carencia de quien después de mucho leer comienza a sustituir los nombres de los teóricos por una suerte de sensación corporal. Él, en otro momento, podría haber pensado esto, agudo, introspectivo, crítico, ácido. Pero hoy no, con una jaqueca que el frío no logró espantar y un dolor en todo el cuerpo sudoroso, asfixiado por una ciudad extraña que después de un trasnoche no se ve amistosa. 
"Prefiero llegar a Barcelona" dijo para sí.

Una vez abajo, esperar el bolso, como cuando en otra época faltaba la comida y tenía que ir con la tarjeta a esperar la harina, el pan, el abrigo. El mismo abrigo con que iba a dar la famosa conferencia. “Cómo me voy al centro?”, se preguntó. Trató de recordar la última vez que había venido a Conce, en tiempos de revolución, cuando todavía tenía sentido esa palabra.

Centenares de caras sin rostro en el terminal, en la cafetería también.

- ¿Por qué hay tanta gente hoy día? -le preguntó al garzón del café, no importándole la conversación, sino más bien cualquier cosa que le hiciera ignorar el dolor de cabeza- ¿pasa algo?

- ¡Sí, pues! -respondió el mesero en tono de reproche- la cuestión de Axe Bahía aquí en el Estadio.

“¿Qué será Axe Bahía?” se preguntó. Recordó aquellos tiempos en que se había interesado por los cultos religiosos afroamericanos y algún Dios perdido; no secuestrado por Nietzsche, sino que oculto en la selva. "Como si esto no fuera la selva", dedujo mientras miraba a algunos de los comensales que ocupaban las otras mesas engullendo "combos", dándole un golpe bajo al hambre.

Mientras tomaba el café comenzó a planear su día. Embotado, no lograba decidir qué era mejor. La conferencia era a las 16:00 horas y no tenía ninguna forma de contactar a su anfitrión. El teléfono se le había quedado en Santiago y no podía llamar a la universidad, ya que vagamente recordaba que le habían dicho que iba a estar cerrada y que no sacaba nada con llamar, que sólo iban a abrir el auditorio poco antes de la conferencia. Decidió salir a la calle a buscar en qué irse al centro. 
Al salir, en la vereda del frente, una micro repleta y un sujeto que vociferaba destinos como si ofreciera helados. El cientista social se percató de que hasta ahí llegaba su fascinación por el realismo mágico y decidió quedarse en tierra. Un colectivo parecía la mejor opción en medio de la intemperie. Así que caminó hasta la esquina, preocupado de que no lo carterearan en medio de ese río de viajeros que van y vienen quizás de dónde.

Los zapatos le apretaban, la cabeza estaba a punto de estallar, su mal genio podía ser fiebre o su fiebre mal genio, no le quedaba claro. Entonces, recordó que esto también le sucedía en los tiempos de revolución y que, por lo tanto, no era producto de la edad, sino parte del cartel de bienvenida que Concepción le tiende a quienes arriban por bus. Un resfrío gratuito.

El colectivo se detuvo sin hacer ruido, como haciendo un guiño cómplice con su malestar. Por supuesto, y no podía ser de otra manera, quedaba sólo un asiento en el vehículo, al lado de un punk criollo, de esos que se pintan el pelo con témpera y rayan la mochila con la archiconocida frase "punk not dead", calcando un discurso de otro mundo; y de otro siglo, por cierto.

- ¿Pasa por el centro?

- Sí.

Más que suficiente. No quería hablar. Ya dentro del colectivo, el dolor era insoportable. Pensó que era una cepa de gripe transgénica, modificada por algún oscuro laboratorio para destruir a los cientistas sociales que devoran bandejas de super cerdo, super pollo y super pavo, porque son las que están al alcance de cualquier bolsillo. Una fórmula química importada por los Chicago Boys para corroerles el cerebro a los disidentes, como si fueran una amenaza al establishment y a la fe en el crecimiento económico. "Sin paranoia, no hay pensamiento crítico", concluyó, sonriendo pese al malestar. 
Adelante, una señora de cabello rubio teñido, elegante para un viernes en la mañana. El colectivero a su lado, insípido, frío, con cara de enigma. El cientista habría especulado en otro momento tratando de imaginar qué pensaba de la vida, qué anhelaba ese hombre teniendo todas las mañanas, literalmente, un camino interminable por recorrer.

Al lado del punk, un tipo mayor, sin cara, mirando por la ventana. En la radio, un paro de los camioneros, el recital de ese "Axe Bahía", el descubrimiento de que Kissinger era primo de Bin Laden... Esto último le pareció surrealista, no podía ser, tenía que haber escuchado mal; en todo caso, aunque fuera cierto, ya a nadie le importaría. Para la gente común y corriente Kissinger es un perfecto desconocido y Bin Laden un Satanás con barba. Punto.

Agradecía que no conversaran, lo que reafirmaba una de sus contradicciones cotidianas: a menudo criticar el poco interés de la gente por la reflexión y por lo que pasa en torno a ellos, pero en días agobiantes -como hoy- desear que no hablen ni piensen, que sólo se comporten como flora y fauna. Sin embargo, una vez más el destino le sacaba la lengua, como al protagonista de La náusea de Sartre. No podía ser de otra forma, tenían que hablar. Y el gatillante, menuda sorpresa, una noticia sobre el desempleo en la radio.

- El gobierno insiste en mantener un actitud optimista frente a la desaceleración económica mundial. El ministro de Hacienda, Nicolás Eyzaguirre, señaló ayer que el aumento de la tasa de desempleo nacional a 9,6\%, durante el último trimestre móvil, se debe a factores estacionales y al retraso en la recuperación de los Estados Unidos, producto de los escándalos financieros que remecieron a Wall Street en las últimas semanas. Señaló que, pese a la inestabilidad regional, Chile está creciendo a un ritmo de $2,8 \%$, y que las exportaciones del sector pesquero, vitivinícola y 
forestal a la Unión Europea aumentarán el 2003, pese a las acusaciones de dumping que enfrentan los salmoneros.

- Puro bla, bla, bla. Igual la cosa está mala, y éstos sacándose los pillos y echándole la culpa a la situación internacional. Yo no sé ya cuánto tiempo que vengo escuchando que la cuestión se va a mejorar, que va a haber pega. Lo que es yo, veo la cosa cada vez peor.

Increíblemente, los rubios cabellos de la señora no se movían mientras hablaba, como si su voz saliera por la rejilla de ventilación.

- Y después tienen la patudez de preguntar por qué la gente no cree en la política. La situación ‘tá mala porque es la política la mala, es el Estado el que no se pone los pantalones -respondió el señor sin cara desde el extremo opuesto de la cabina.

El cientista no lo podía creer. Con dos comentarios ya supo anticipar, como con una suerte de facultad adivinatoria, propiciada por la fiebre y el dolor, que esto no iba a parar. Que se le había ocurrido subirse al único potro de tortura con ruedas existente en el país. Si no le hubiera dolido la cabeza, se habría puesto a hablar de la reducción de tasas arancelarias contemplada en el Acuerdo de Asociación Política, Económica y de Cooperación con la Unión Europea; de que aquello que sus compañeros de viaje atribuían a una suerte de predestinación calvinista, conjura cósmica o fuerza telúrica, es perfectamente explicable desde la racionalidad científica por la trilogía de las "ciones" (privatizaciones, desregulaciones y liberalizaciones), magistralmente esculpida por Hans-Peter Martin y Harald Schumann en La trampa de la globalización.

Imposible relatarles en quince minutos que producto del ascenso de Margharet Thatcher en Gran Bretaña 
y Ronald Reagan en Estados Unidos, a principios de los '80, las democracias liberales le abrieron de par en par las puertas del Estado a las elucubraciones de Harold Demsetz; entregándole el último bastión de lo social, la política, a los laboratoristas económicos de la Escuela de Chicago, de UCLA y el Instituto Tecnológico de Massachussets, quienes no conformes con dominar el centro sedujeron a los jóvenes acomodados del mundo subdesarrollado y los convencieron de que era mejor hablar de sus comarcas como continentes "en vías de desarrollo" y "emerging markets".

Los transformaron en yuppies de la periferia y les vendieron la receta mágica de la eficacia inexpugnable de lo privado y de la apriorística inoperancia de lo fiscal. Como también que ese modelo, maquillado con neones, rascacielos de vidrio y olor a pollo frito, sería la panacea del progreso para países como Chile, donde la nación se construyó "desde arriba", a partir del Estado, de la alta sociedad a cargo de los "negocios públicos", a la manera descrita por Mario Góngora. Contexto por lo demás muy distinto al europeo, donde ambas estructuras surgieron, $\mathrm{o}$ más bien decantaron, casi en paralelo.

Titánico aclararles que el Estado, esa estructura política y jurídica de la nación sobre un territorio, es un término propio de la modernidad, como afirma Norberto Bobbio en Estado, gobierno y sociedad, aplicable sólo a partir de las formaciones políticas nacidas de la crisis del medioevo. $\mathrm{O}$ que el Estado es un sustantivo abstracto y no el Palacio de la Moneda, por ejemplo; y que, por ello, a fin de cuentas, no es más que un imaginario colectivo reposando sobre una relación de dominio de hombres sobre hombres, que tiene en el monopolio legítimo de la fuerza y de la recaudación de impuestos su única justificación, como sentencia Max Weber en Economía y sociedad, o Norbert Elias en El proceso de la civilización.

Para el cientista era más cómodo observar el espectáculo etnográfico refugiado tras su abrigo y lidiando con 
su jaqueca. Pero, consciente de que el cosquilleo crítico es un mal de formación, optó por dar rienda suelta a un improvisado experimento sociológico: jugar al moderador y llevar el debate a sus bases conceptuales para así acercarse, aunque fuese con el rabillo del ojo, como pretenden los constructivistas, a las cosmovisiones de este verdadero "zoo" de sujetos populares.

- Pero, ¿qué es para usted el Estado? -preguntó al hombre sin cara, tratando de hacerse el cordial.

El tipo se puso serio, mientras el punk -que olía a trasnoche- los miró a ambos con cara de asco. El silencio duró unos diez segundos.

- El Estado podría ser lo que manda el presidente... -titubeó- lo que hace el Presidente de la República, como el gobierno, como los servicios, como salud, trabajo, bienestar pa'l país.

- El Estado es lo que ha dado el gobierno-interrumpió el chofer, rompiendo su silencio espectral- lo que ha hecho con tanto adelanto, sobre todo con los comerciantes... con los comerciantes chicos po'... A mí mismo, que tengo un negocito de abarrotes que lo atiende mi señora, el Estado me dio para que mi hijo hiciera un curso ¿ve?... Eso lo paga el Estado, y ha sido una gran oportunidad que le ha dado. Con eso, harta gente ha encontrado trabajo ahora, gente que se quedó sin pega pa' la crisis asiática.

La mujer intervino de nuevo, como tratando de redondear la idea, mientras el chofer se pasaba un semáforo en rojo por culpa de la charla anotándose unos bocinazos de descrédito.

- Mire, yo creo que el Estado es como un conjunto de instituciones, de personas, que de alguna ma- 
nera están rigiendo los derechos del país. Tenemos que tener una cabeza, tenemos que tener los tres poderes para tener un Estado...

- ¡El Estado es un imperio puh señora! -rebatió el punk, visiblemente afectado por un ataque de lucidez, ira y trasnoche- algo ficticio más que nada, sin ningún fundamento. ¿O no ve usted que los partidos casi siempre terminan con los pacos repartiendo lumazos? Si uno se va a puro divertir y a la final termina cooperando...

Para distender el ambiente, el cientista retomó la interrogante inicial.

- Entonces, el Estado no es lo mismo que la nación... -la cabina volvió a enmudecer y Zalo Reyes quedó de fondo con su lágrima en la garganta, que sonaba atascada en el baffle.

- No pus caballero, la nación es el país completo -agregó la señora- con todas sus capitales, con todas sus provincias, es todo el contexto de un país.... nación y país son exactamente lo mismo, ¿no es cierto? -buscando la aprobación del chofer.

- Yooo... no estoy muy culto en eso, porque no es parte de mi trabajo. Los políticos yo creo que ven eso. Usted sabe que uno se basa en lo de uno no más y los políticos ven lo de ellos.

El silencio volvió a cobrar protagonismo.

- La nación sería el país, en el sentido político. Por ser, en este momento estamos en una situación mala y todo recarga en la política -añadió el que iba pegado a la ventanilla. 
"Sorprendente", pensó el cientista. Ninguna referencia a la idea de nación como un grupo humano amplio, mucho más vasto que el pueblo o la provincia, con un pasado que se vive como propio y común; menos al anhelo de ver a esa comunidad junta e independiente, como sostiene Jean Baptiste Duroselle, en Europa, de 1815 a nuestros días. Aunque lo que sí advirtió en esa especie de simbiosis entre nación y país, fue una imagen sumamente administrativa, geopolítica y casi estratégica de la nación, que le recordó poderosamente que Chile adquirió su independencia casi en forma fortuita, producto del encarcelamiento del rey Fernando VII. Hecho que Mario Góngora resalta en su Ensayo histórico sobre la noción de Estado en Chile en los siglos XIX y $X X$, al destacar que los responsables del joven Estado republicano tuvieron que construir una idea de nación cimentada sobre himnos, banderas, escudos, escarapelas y todo tipo de símbolos patrios; soportes concretos, materiales, llamativos. Como también que, para un país escasamente poblado y territorialmente muy extenso, con una marcada trayectoria como Capitanía General durante la Conquista y buena parte de La Colonia, más tres guerras durante el siglo XIX, el imaginario castrense (fuerte, jerárquico y centralista) no pudo ser sino capital en la construcción del carácter nacional.

Sí. Chile era una nación opaca, con un sentido tutelar y proteccionista de la autoridad. Una nación enfermiza por el orden, por las leyes. Una nación aún guiada por la idea de que las costumbres pueden cambiarse por decreto, como postulaba la Constitución moralista de 1823, y cuya clase política seguía convencida de que la historia pasa por efemérides, que basta con aprobar un proyecto de ley para crear un día del patrimonio cultural, un día de la cultura, o uno de la unidad nacional. Un país para vasallos donde la república se vive más como monarquía, donde el presidente es visto más que como estadista, como un rey que despacha edictos para mantener a raya a sus súbditos. Una nación cuya memoria se reduce al 18 de septiembre, al 21 de 
mayo, a Arturo Prat y Bernardo O'Higgins. Próceres, gloria, estatuas, desfiles, ofrendas florales, dos pies de cueca y el resto cumbia, cumbia y más cumbia; ramadas en el desértico Norte Grande y en la pampa magallánica, aunque los contextos para nada encajen.

- No es na' la política no-más mi amigo. Lo que pasa es que aquí en este mundo tenemos que pagarlas todas- le respondió el chofer al hombre sin cara-, hemos sido malos y el de arriba no más sabe la situación que nos está mandando. Por ejemplo, 'tamos viendo que aquí no nos está lloviendo y en el norte está lloviendo donde no llueve; en otras partes hay sequía y custiones; entonces, no me cabe la menor duda que el mundo se va a acabar.

De súbito, las cavilaciones del cientista tuvieron que amoldarse al discurso popular del apocalipsis; a esa idea de vivir al filo del Juicio Final que parece embargar a todas las generaciones desde el Nuevo Testamento y que permanentemente se actualiza: las dos guerras mundiales, el equilibrio del terror entre EE.UU. y la URSS, la caída de las Torres Gemelas, etc. Era previsible, a la idea del progreso indefinido se le había asestado un golpe fatal a partir de 1914. “El progreso es bueno, pero también nos puede destruir, los excesos se pagan con castigos divinos", es lo que pensarían las mayorías, imaginó.

- Ha habido tanto cambio ahora, tanta violencia -prosiguió el conductor-, todo lo que ha pasado en Estados Unidos; 'ta todo cambiado pienso yo. Se está viendo tanta cosa que antes existía, pero no se comunicaba como se comunica ahora... Como que la gente está más mala ahora, más egoísta... Quiere tener, pero no quiere que la otra persona tenga.... Las mismas guerras confunden... la gente está como toda confundida con eso... Esos países del Medio Oriente que siempre están peleando, 
siguen en guerra todavía. ¡Imagínese como están, si se matan unos con otros! No llegan a ningún acuerdo de nada. Por eso, yo creo que la gente está más mala, porque la misma tele le enseña maldades a la gente... Si en las películas uno ve hasta cómo se hacen los asaltos... después la gente hace lo mismo en la calle...

"Las guerras de otras latitudes son para ellos una mera película", pensó el cientista. "Lo único que les queda en la retina son imágenes de ruinas polvorientas, un avión que parece recortado de los 'Archivos secretos $X^{\prime}$ sobrevolando una cadena montañosa, el lanzamiento de un misil desde un barco anclado en un Golfo Pérsico que jamás verán con sus propios ojos".

- La globalización, ¿no es cierto? -exclamó, poniendo un anzuelo para desatar reacciones.

- Sí poh, el poder -afirmó el punk, convencido. Los demás callaron.

- Es que el hombre lo ha hecho mal, la ciencia lo ha hecho mal. O sea, vamos avanzando, pero a la vez uno va quedando atrás. Eso se ve también en la riqueza y en la pobreza; unos ganan más, otros menos. Unos pasan encima de otros... -añade el hombre sin cara.

- Tanta cosa que hablan en la tele de la globalización y toda la custión; al final no comprendo qué es lo que quieren decir con eso... -responde el colectivero.

- La globalización yo la veo como un contexto que existe dentro de un país, dentro de un gobierno -esboza la mujer-, es estar inserto en todos los sistemas que a uno le competen. Es todo un 
contexto de administración que está inserto en el Estado o en el gobierno de turno, o en la nación. Claro que eso ha existido siempre, pero el concepto lo vienen usando hace unos diez años me parece, como que ahora le han dado más énfasis, aplicado al Estado, servicios públicos, que están conectados a nivel mundial. La tecnología está avanzando a pasos agigantados, la igualdad de condiciones ha evolucionado mucho... pero se ha perjudicado mucho a los niños, a los adolescentes, porque ahora se les deja demasiado solos. Estamos mejor porque la mujer tiene más oportunidades de trabajar, pero estamos más egoístas. La juventud ha perdido mucho los valores; pero la culpa no la tienen ellos, la tienen los adultos... A veces por necesidad, a veces por ego, depende de la clase social. Para mí, el consumismo y la televisión tienen la culpa, las dos cosas juntas.

A esas alturas la migraña tendía a disiparse y el cientista se concentraba en el meollo de su venida a la ciudad, la globalización. En efecto, si algo podían relacionar con globalización esas personas eran las comunicaciones vía satélite, palpables sólo desde fines de los 70. “Esa es la cara visible, si es que existe una", se dijo. Idea que, por lo demás, no estaba tan lejos de los autores que le han dado varias vueltas de tuerca al tema. "La globalización es política, tecnológica y cultural, además de económica”, pensó citando mentalmente Un mundo desbocado de Anthony Giddens. Manuel Castells hacía lo propio en La era de la información, concluyó, señalando que, desde la década de los ochenta, se viene gestando una nueva economía, que es informacional porque basa su productividad y competitividad en la capacidad para generar, procesar y aplicar la información y el conocimiento; y global porque la producción, el consumo y la circulación de capital se articulan y coordinan en tiempo real. Se trata de una economía interconectada y profundamente interdependiente, decía el sociólogo español, y, prueba de ello, es la crisis asiática, aquélla que el 
chofer asoció automáticamente con la cesantía.

"George Soros tiene razón", pensó. El gran problema es que este sistema capitalista es global en lo económico, pero no en lo político. De hecho, es particularmente difícil imaginar un sistema político globalizado. Ni siquiera la Unión Europea se ve cerca de ese logro. Aunque tampoco aspira a ello, si se toma en cuenta que nació como Comunidad Económica y su máxima meta, más que el famoso TPI, es y será su moneda única, el euro, que ya tiene bastante descontentos a muchos europeos de carne y hueso, que han visto disminuido de golpe y porrazo su poder adquisitivo, otrora orgullo del Estado del Bienestar.

En efecto, la idea del riesgo permanente, la atomización de los acontecimientos, la imprevisibilidad como nueva regla de las relaciones laborales, la decadencia de los "empleos de por vida", el subempleo y el empleo precario, son testimonios de que el capitalismo le declaró la guerra a la mano de obra y se la ganó, como dice Jeremy Rifkin en $E l$ fin del trabajo. Pero cómo explicarles a esas personas un proceso tan solapado como sinuoso, que en el Primer Mundo viene en avance desde los acuerdos de Bretton Woods en la década de los 40. Cómo mostrarles que, más allá de los vaivenes políticos a que estuvo condenada Latinoamérica en los 70 y 80, la liberación de las ataduras del capital en los países desarrollados, su fuga de la esfera económica nacional, se iba produciendo lentamente mientras la población del mundo, separada por la Cortina de Hierro, vivía con el alma en un hilo esperando que alguien apretara el botón.

Abaratar costos, buscar mano de obra barata en los países del Tercer Mundo, apostar a la seguidilla de privatizaciones que tuvieron lugar en la mayoría de los Estados de la región durante los 90, todas acciones que los dueños del capital aprovecharon para producir más a menor precio, competir en nuevos mercados y eliminar empleos en los países del centro, como si se tratase de máquinas vetustas.

Desempleo estructural, analfabetismo funcional, 
el nuevo karma de los obreros industriales del centro no es en absoluto comparable con el vivir cotidiano de estas personas. "Habitantes que ven pasar el desarrollo a través de la ventanilla de un colectivo", reflexionaba el cientista. Gente condenada a experimentar el "qué" (más desempleo, menos poder adquisitivo, más desconfianza), pero no a entender el "cómo" (fusiones empresariales, economías de escala, tecnificación de los procesos productivos, desindicalización, desrregulación en materia laboral y económica, "gendarmerización" del Estado), ni menos el "porqué" (mayor concentración de la riqueza, menos manos repartiéndose los naipes, el mundo convertido en una pirámide de paredes lisas).

"La globalización, más bien esta globalización, es un gigante con pies de barro", pensó el cientista. Un arma de doble filo cimentada en la mayor riqueza de un grupúsculo y en el empobrecimiento de la mayorías. Unos ganan y los demás pierden, como describen Martin y Schumann en La trampa de la globalización. Esta aceleración de los intercambios tiende puentes sobre los países, pero a la vez los disgrega. Nace de la hiperdensidad de las ciudades, del fin de los horarios y del auge del trabajo por objetivos, del "arréglatelas como puedas" y de la racionalidad científica como nueva fe.

Se apoya en la democracia como verdad fundadora y en la lógica del mercado como piedra de toque para cualquier objeción moral. Bajo un discurso oficialista en favor de los derechos humanos, sigue propiciando una explotación del hombre que llega a lo infrahumano por acostumbramiento. "Todos los hombres son iguales, pero unos son más iguales que otros", decía George Orwell.

"Este sistema es perverso" resumió el cientista. Desde los 80, y progresivamente, los impuestos sobre el capital se han batido en retirada para golpear a los que más lo sienten: los consumidores; como indica Soros en $\mathrm{La}$ crisis del capitalismo global. Si algún gobierno decide subir 
la tributación a las empresas, sabe que ello significa que los capitalistas traspasarán, sin pensarlo dos veces, el alza a los ciudadanos. "Tratar de reducir la inequidad en la distribución del ingreso es un tiro por la culata", pensó. No se logra equilibrio, sólo se nivela hacia abajo, se empobrece al grueso de la población. El Estado se vuelve el rehén y los ciudadanos sus carceleros, mientras el capital juzga y dicta condena desde las sombras.

- Poder. Es todo-insistió el punk, mientras el colectivo pasaba frente a un inmenso aviso de Falabella, donde un muchacho aparecía vestido como él -; por eso hay que rebelarse, la rebeldía es lo único que queda.

- ¿¿Qué rebeldía, niño?! El común de los mortales tiene que trabajar, eso es lo único que queda- dijo la señora.

Y entonces, algo extraño le pasó al cientista. No fue una sensación que se fuera clarificando paulatinamente, como cuando se va aprehendiendo una verdad a través de sucesivas lecturas, sino más bien un choque. Como cuando su esposa le prendía la luz de la habitación mientras leía. Una evidencia dolorosa: tuvo la convicción, por un segundo, de que en la tarde iba a hablar mentiras. De que él y los autores en que se apoyaba ofrecerían a su público una lectura lógica y descarnada del curso de la humanidad hasta nuestros días. Sin embargo, sería sólo eso, una lectura, como tantas otras. Él explicaría el cómo y el porqué, pero nada podría hacer para modificar el lecho del río. Nada de lo que dijera a sus oyentes haría que vivieran en un mundo mejor.

Fue ahí, sentado entre el punk y la puerta, teniendo que preguntar en qué calle bajarse del colectivo, corroborando la sensación de ser minoría, donde le pareció que la VERDAD era aquella que se estaba desarrollando en la conversación. A pesar de que estaba inmerso en el debate 
objetivismo/ perspectivismo, el mismo en el que las Ciencias Sociales se encuentran hoy, nunca le había parecido tan evidente que la historia de los acontecimientos que precedieron a las concepciones de Estado y de Globalización, como las conocemos ahora, no era la historia real.

Sabía que la historia se hacía parte de la pretensión de buscar explicaciones para ciertos fenómenos, y que la posición del cientista era particularmente privilegiada en ese sentido. Sin embargo, ¿qué pasaba con los sujetos de carne y hueso?, ¿acaso no eran ellos con sus luchas y avasallamientos de unos por sobre otros los que eran el cuerpo de lo que el hablaba y pensaba?, ¿acaso no era su vivencia, la verdad de la gran mayoría (y no la de él), la que sí importaba, aquella de la cual cualquiera que diga preocuparse de lo social, debería atender? Recordó a Morris Berman, quien ha sacado a relucir la historia de una forma corporizada en los sujetos reales, de la misma forma en que estaba él ahí, apretujado entre un punk y una puerta sin atreverse a preguntar ni a decir nada más, ni siquiera dónde tenía que bajarse.

Por otra parte, Baudrillard había acosado incluso sus sueños lo suficiente como para saber que gran parte de las cosas de las que iba a hablar en la tarde, para muchos no tenían sentido, por ejemplo, la historia. Claro, siempre estaba la posibilidad de decir que los sujetos que estaban ahí sólo experienciaban lo que los discursos oficiales les permitían experienciar, y que su mundo o self estaba limitado por el poder, por ejemplo, en el caso del punk. Pero eso no servía de nada. De todas formas, las únicas personas que podrían socorrerlo si él se desmayaba en ese momento, sofocado por los años y el cansancio, eran los sujetos que estaban ahí. Los únicos que sabían dónde quedaba el centro eran aquellos enfrascados en esa cabina de automóvil. No les servía absolutamente de nada lo que él les pudiera decir, así como no les iba a servir absolutamente de nada a quienes iban a estar en la tarde escuchando su conferencia. 
El mundo de todos ellos, así como el de él mismo, estaba determinado por una lucha de dos fuerzas que ya no eran el marxismo y el capitalismo, sino más bien la posibilidad de la vida en la cotidianeidad y el develamiento de complots y especulaciones dirigidas por un grupo de sujetos que, quizás, podrían caber en ese mismo colectivo. Recordó a aquel Dios del que había escuchado en la mañana, Axe Bahía, y pensó que quizás iba sentado ahí, adelante del colectivo, mirándolo a los ojos. Era a la vez el sujeto sin cara del otro lado y el rostro de la señora de rubia cabellera. Era todos los sujetos que había visto en el terminal, y todos estaban preguntándole cómo se podían juntar ambos mundos, el de la cotidaneidad y el de las grandes estructuras, preguntándole dónde bajarse, dónde bajarse...

- Señor, despierte, yo llego hasta aquí... ¿dónde dijo que se bajaba usted?

- ¿Ah, cómo?... sí, en el centro.

- Oiga, pero si ya llegamos al terminal, y yo no vuelvo al tiro, le aviso.

- Bueno- dijo el cientista- yo tampoco.

\section{Bibliografía}

1. Baudrillard, J (1993).

2. Berman, M. (1989).

3. Bobbio, Norberto (1989).

4. Duroselle, Jean Baptiste $(19$

5. Elias, N. (1993). El proceso de la civilización. Fondo de Cultura

6. Foucault, M. (1992).

7. Giddens, A. (2000).

8. Gongóra, M. (1988).
La Ilusión del Fin o la Huelga de los acontecimientos. Editorial Anagrama, Barcelona, España.

Cuerpo y Espíritu. La historia oculta de Occidente. Editorial Cuatro Vientos, Santiago, Chile.

"Estado, gobierno y sociedad". Fondo de Cultura Económica, México.

Económica, Buenos Aires.

Microfísica del Poder. Ediciones de La Piqueta, Colección Genealogía del Poder, $\mathrm{N}^{\circ} 1$. Tercera Edición.

Un mundo desbocado. Los efectos de la globalización en nuestras vidas. Editorial Taurus, Colombia.

Ensayo histórico sobre la noción de Estado en Chile en los siglos XIX y XX. Editorial Universitaria, Santiago, 
Chile.

9. Gutierrez, J. y Delgado, J. (1995

Teoría de la Observación. En Juan Delgado y Juan Gutierrez (1999) Métodos y técnicas cualitativas de investigación en Ciencias Sociales, Tercera Edición. Editorial Síntesis.

10. Jocelyn-Holt, A. (1997). El peso de la noche. Nuestra frágil fortaleza histórica. Editorial Ariel, Argentina.

11. Luttwak, E. (2000). Turbocapitalismo. Quienes ganan y quienes pierden en la globalización. Editorial Crítica, Barcelona, España.

12. Martin, H. \& Schumann, H. (2001).

La trampa de la globalización. El ataque contra la democracia y el bienestar. Editorial Taurus, España.

13. Orwell, Goerge (1963).

Animal Farm. Penguin Books, London.

14. Rifkin, J. (1996).

El fin del trabajo. Nuevas tecnologías contra el puesto de trabajo: el nacimiento de una nueva era. Paidós, España.

15. Soros, G. (1999).

La crisis del capitalismo global. La sociedad abierta

16. Weber, M (1987). en peligro. Editorial Debate, Madrid, España.

Economía y Sociedad. Fondo de Cultura Económica, México. 